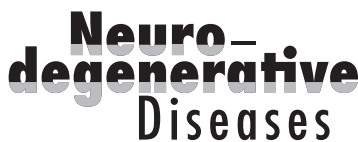

\title{
Can the Calcium Hypothesis Explain Synaptic Loss in Alzheimer's Disease?
}

\author{
Elena Popugaeva ${ }^{a} \quad$ llya Bezprozvannya, b \\ a Laboratory of Molecular Neurodegeneration, St. Petersburg State Polytechnical University, St. Petersburg, Russia; \\ ${ }^{b}$ Department of Physiology, UT Southwestern Medical Center at Dallas, Dallas, Tex., USA
}

\section{Key Words}

Alzheimer's disease - Calcium signaling · Synapse ·

Mushroom spines $\cdot$ Neuronal store-operated channels

\begin{abstract}
Alzheimer's disease (AD) is the threat of modern humankind that is provoked by increased human lifespan. Despite extensive studies on AD pathology for more than 100 years, there are no disease-preventing therapies. Growing evidence suggests the role of calcium $\left(\mathrm{Ca}^{2+}\right)$ in the pathogenesis of AD. The main purpose of the article is to understand whether modern science is able to explain the synapse loss observed in early $A D$ and discuss the role of $\mathrm{Ca}^{2+}$ hypothesis in it. Based on results obtained in our laboratory and others, we propose that familial AD-associated mutations in presenilins cause a $\mathrm{Ca}^{2+}$ overload of endoplasmic reticulum stores which leads to compensatory downregulation of the neuronal store-operated $\mathrm{Ca}^{2+}$ (nSOC) entry pathway. We propose that synaptic $\mathrm{nSOC}$ is necessary for the stability of mature synaptic spines and that dysfunction of this pathway may play an important role in synaptic and memory loss in $A D$.

(c) 2013 S. Karger AG, Basel
\end{abstract}

() 2013 S. Karger AG, Basel

$1660-2854 / 13 / 0133-0139 \$ 38.00 / 0$
Alzheimer's disease (AD) is a well-known pathology destroying the human brain and the personality. The majority of known facts about $\mathrm{AD}$ pathogenesis come from discoveries in mouse models mimicking genetically caused cases of familial AD (FAD). Although FAD covers about $1-2 \%$ of all $\mathrm{AD}$ cases, the mouse models and clinical data agree that synapse loss is the major hallmark of $\mathrm{AD}$ that results in memory loss.

What is the physiological substrate of memory? Expression of long-term potentiation in response to brief high-frequency stimulation of synaptic ends in the hippocampus is strongly correlated with learning and memory $[1,2]$. Long-term potentiation takes place in small dendritic protrusions called dendritic spines. Based on their size and shape, spines are divided into three groups: stubby, thin and mushroom. It has been proposed that the mushroom spines are stable 'memory spines', and therefore, they store memories, and that thin spines are 'learning spines' that serve as physical substrates for the formation of new memories $[3,4]$. Since loss of memories is a hallmark of $\mathrm{AD}$, we and others previously proposed that mushroom spines are more likely to be eliminated during AD progression [5-7].

What mechanism is responsible for mushroom spine elimination? The dominant amyloid- $\beta$ (A $\beta$ )-based hy-

Ilya Bezprozvanny

Department of Physiology, ND12.200AA, UT Southwestern Medical Center at Dallas 5323 Harry Hines Blvd.

Dallas, TX 75390-9040 (USA)

E-Mail Ilya.Bezprozvanny@UTSouthwestern.edu 
pothesis of $\mathrm{AD}$ states that soluble $\mathrm{A} \beta 42$ peptides possess synaptotoxic effects. $A \beta$ could mediate the synapse loss through the potentiation of the $\mathrm{N}$-methyl-D-aspartate receptor. Stimulation of the N-methyl-D-aspartate receptor triggers excessive calcium $\left(\mathrm{Ca}^{2+}\right)$ influx that activates calcineurin, a $\mathrm{Ca}^{2+}$-activated phosphatase whose activation leads to synapse weakening and $\mathrm{AD}$-associated spine loss [8]. However, many facts speak for early $\mathrm{Ca}^{2+}$ abnormalities that precede or even happen in the absence of $\mathrm{A} \beta \mathrm{pa}$ thology $[9,10]$. The $\mathrm{Ca}^{2+}$ hypothesis of brain aging and $\mathrm{AD}$ states for sustained changes in $\mathrm{Ca}^{2+}$ homeostasis could provide the common pathway for aging and the neuropathological changes associated with $\mathrm{AD}$ [11]. In particular, multiple evidence points to disregulated endoplasmic reticulum (ER) $\mathrm{Ca}^{2+}$ homeostasis in aging and $\mathrm{AD}$ neurons $[9,10]$. There are two channels in the ER that mediate $\mathrm{Ca}^{2+}$ release: ryanodine receptors (RyanR) and inositol triphosphate receptors (IP3R). Taking into account that IP3R predominantly resides in the soma, whereas RyanRmediated signals are more distinct in dendritic spines and presynaptic terminals $[12,13]$, the input of abnormal RyanR function on postsynaptic $\mathrm{Ca}^{2+}$ signaling could be stronger than IP3R-mediated signaling. Thus, blocking RyanR (for example with dantrolene) appears to be a potential way to stabilize $\mathrm{Ca}^{2+}$ signals in AD brains. However, inconsistent results were obtained when dantrolene was tested in AD mouse models [14-17].

In addition to RyanR and IP3R, our recent data show that presenilins (PS; mutations in PS are associated with FAD) could play the role of a low conductance ER $\mathrm{Ca}^{2+}$ leak channel, and many FAD mutations disrupt this function [18]. This idea remains controversial [19], but our hypothesis has found confirmation in a recent breakthrough study that demonstrates the crystal structure of a bacterial homologue of PS (PSH) [20]. In agreement with our mutagenesis data [21], the authors found that PSH has a water-filled hole that is large enough to allow the passage of small ions, suggesting that PSH may function as an ion channel. Our hypothesis was also supported by a recent unbiased screen for $\mathrm{Ca}^{2+}$ homeostasis modulators [22]. These authors demonstrated that knocking down PS2 dramatically reduced the ER $\mathrm{Ca}^{2+}$ leak rate in HEK293 cells, consistent with the 'leak channel' hypothesis [22, 23].

What is the connection between impaired ER $\mathrm{Ca}^{2+}$ leak function, $\mathrm{ER} \mathrm{Ca}^{2+}$ overload and synaptic loss in $\mathrm{AD}$ ? We previously proposed that abnormalities in $\mathrm{ER} \mathrm{Ca}^{2+}$ handling may be linked to destabilization of mushroom postsynaptic spines $[6,7]$. Consistent with this idea, in recent experiments, we observed a significant downregulation of the synaptic neuronal store-operated $\mathrm{Ca}^{2+}$ (nSOC) entry pathway in PS mutant neurons [Sun and Bezprozvanny, unpubl. data]. In agreement with our findings, impaired SOC was reported by several groups for PS mutant cells [16, 24-28]. Our results further indicate that reduced postsynaptic SOC leads to destabilization and elimination of mushroom spines - sites of memory storage [Sun and Bezprozvanny, unpubl. data].

Based on obtained results, we propose that synaptic ER $\mathrm{Ca}^{2+}$ overload and compensatory downregulation of the synaptic nSOC pathway play an important role in synaptic loss in $\mathrm{AD}$ and aging brains. Our results suggest that upregulation of the synaptic nSOC pathway may yield therapeutic benefits for the treatment of $\mathrm{AD}$ and age-related memory problems.

\section{Acknowledgments}

I.B. is a holder of the Carl J. and Hortense M. Thomsen Chair in Alzheimer's Disease Research. This work was supported by Welch Foundation I-1754 (I.B.), National Institutes of Health grant R01NS080152 (I.B.), by the contract with the Russian Ministry of Science 11.G34.31.0056 (I.B.), and by the Dynasty Foundation grant DP-B-11/13 (E.P.).

\section{References}

$>1$ Bliss TV, Collingridge GL: A synaptic model of memory: long-term potentiation in the hippocampus. Nature 1993;361:31-39.

- Trommald M, Hulleberg G, Andersen P: Long-term potentiation is associated with new excitatory spine synapses on rat dentate granule cells. Learn Mem 1996;3:218-228.

3 Kasai H, Matsuzaki M, Noguchi J, Yasumatsu N, Nakahara H: Structure-stability-function relationships of dendritic spines. Trends Neurosci 2003;26:360-368.

\footnotetext{
4 Bourne J, Harris KM: Do thin spines learn to be mushroom spines that remember? Curr Opin Neurobiol 2007;17:381-386.

5 Tackenberg C, Ghori A, Brandt R: Thin, stubby or mushroom: spine pathology in Alzheimer's disease. Curr Alzheimer Res 2009;6: 261-268.

6 6 Popugaeva E, Supnet C, Bezprozvanny I: Presenilins, deranged calcium homeostasis, synaptic loss and dysfunction in Alzheimer's disease. Messenger 2012;1:53-62.
}

\footnotetext{
7 Bezprozvanny I, Hiesinger PR: The synaptic maintenance problem: membrane recycling, $\mathrm{Ca}^{2+}$ homeostasis and late onset degeneration. Mol Neurodegener 2013;8:23.

8 Wu HY, Hudry E, Hashimoto T, Kuchibhotla K, Rozkalne A, Fan Z, Spires-Jones T, Xie H, Arbel-Ornath M, Grosskreutz CL, Bacskai BJ, Hyman BT: Amyloid beta induces the morphological neurodegenerative triad of spine loss, dendritic simplification, and neuritic dystrophies through calcineurin activation. J Neurosci 2010;30:2636-2649.
} 
9 Bezprozvanny I, Mattson MP: Neuronal calcium mishandling and the pathogenesis of Alzheimer's disease. Trends Neurosci 2008; 31:454-463.

$>10$ Stutzmann GE: The pathogenesis of Alzheimers disease is it a lifelong 'calciumopathy'? Neuroscientist 2007;13:546-559.

11 Khachaturian ZS: Calcium, membranes, aging, and Alzheimer's disease. Introduction and overview. Ann NY Acad Sci 1989;568:14 .

12 Smith IF, Hitt B, Green KN, Oddo S, LaFerla FM: Enhanced caffeine-induced $\mathrm{Ca}^{2+}$ release in the $3 \times \mathrm{Tg}-\mathrm{AD}$ mouse model of Alzheimer's disease. J Neurochem 2005;94:1711-1718.

$\checkmark 13$ Cheung KH, Mei L, Mak DO, Hayashi I, Iwatsubo T, Kang DE, Foskett JK: Gain-of-function enhancement of IP3 receptor modal gating by familial Alzheimer's disease-linked presenilin mutants in human cells and mouse neurons. Sci Signal 2010;3:ra22.

14 Oules B, Del Prete D, Greco B, Zhang X, Lauritzen I, Sevalle J, Moreno S, Paterlini-Brechot P, Trebak M, Checler F, Benfenati F, Chami $\mathrm{M}$ : Ryanodine receptor blockade reduces amyloid-beta load and memory impairments in Tg2576 mouse model of Alzheimer disease. J Neurosci 2012;32:11820-11834.

15 Chakroborty S, Briggs C, Miller MB, Goussakov I, Schneider C, Kim J, Wicks J, Richardson JC, Conklin V, Cameransi BG, Stutzmann GE: Stabilizing ER $\mathrm{Ca}^{2+}$ channel function as an early preventative strategy for Alzheimer's disease. PLoS One 2012;7:e52056.
16 Zhang H, Sun S, Herreman A, De Strooper B, Bezprozvanny I: Role of presenilins in neuronal calcium homeostasis. J Neurosci 2010;30: 8566-8580.

17 Peng J, Liang G, Inan S, Wu Z, Joseph DJ, Meng Q, Peng Y, Eckenhoff MF, Wei H: Dantrolene ameliorates cognitive decline and neuropathology in Alzheimer triple transgenic mice. Neurosci Lett 2012;516:274-279.

$18 \mathrm{Tu} \mathrm{H}$, Nelson O, Bezprozvanny A, Wang Z, Lee S-F, Hao YH, Serneels L, De Strooper B, $\mathrm{Yu}$ G, Bezprozvanny I: Presenilins form ER calcium leak channels, a function disrupted by mutations linked to familial Alzheimer's disease. Cell 2006;126:981-993.

19 Shilling D, Mak DO, Kang DE, Foskett JK: Lack of evidence for presenilins as endoplasmic reticulum $\mathrm{Ca}^{2+}$ leak channels. J Biol Chem 2012;287:10933-10944.

20 Li X, Dang S, Yan C, Gong X, Wang J, Shi Y: Structure of a presenilin family intramembrane aspartate protease. Nature 2013;493: 56-61.

21 Nelson O, Supnet C, Tolia A, Horre K, De Strooper B, Bezprozvanny I: Mutagenesis mapping of the presenilin 1 calcium leak conductance pore. J Biol Chem 2011;286:2233922347.

22 Bandara S, Malmersjö S, Meyer T: Regulators of calcium homeostasis identified by inference of kinetic model parameters from live single cells perturbed by siRNA. Sci Signal 2013;6:ra56.
23 Bezprozvanny I: Presenilins and calcium signaling - systems biology to the rescue. Sci Signal 2013;6:pe24.

24 Leissring MA, Akbari Y, Fanger CM, Cahalan MD, Mattson MP, LaFerla FM: Capacitative calcium entry deficits and elevated luminal calcium content in mutant presenilin-1 knockin mice. J Cell Biol 2000;149:793-798.

25 Yoo AS, Cheng I, Chung S, Grenfell TZ, Lee $\mathrm{H}$, Pack-Chung E, Handler M, Shen J, Xia W, Tesco G, Saunders AJ, Ding K, Frosch MP, Tanzi RE, Kim TW: Presenilin-mediated modulation of capacitative calcium entry. Neuron 2000;27:561-572.

26 Herms J, Schneider I, Dewachter I, Caluwaerts N, Kretzschmar H, Van Leuven F: Capacitive calcium entry is directly attenuated by mutant presenilin-1, independent of the expression of the amyloid precursor protein. J Biol Chem 2003;278:2484-2489.

27 Akbari Y, Hitt BD, Murphy MP, Dagher NN, Tseng BP, Green KN, Golde TE, LaFerla FM: Presenilin regulates capacitative calcium entry dependently and independently of gamma-secretase activity. Biochem Biophys Res Commun 2004;322:1145-1152.

28 Bojarski L, Pomorski P, Szybinska A, Drab M, Skibinska-Kijek A, Gruszczynska-Biegala J, Kuznicki J: Presenilin-dependent expression of STIM proteins and dysregulation of capacitative $\mathrm{Ca}^{2+}$ entry in familial Alzheimer's disease. Biochim Biophys Acta 2009;1793:10501057. 